\title{
1 Retrograde suppression of post-tetanic potentiation at the mossy fiber-CA3 2 pyramidal cell synapse
}

Abbreviated Title: Activity-dependent suppression of PTP

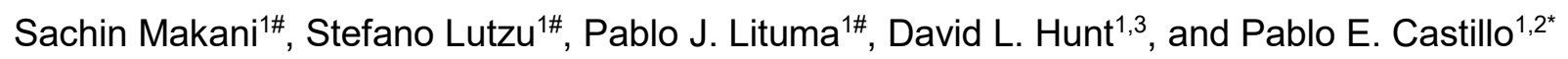

${ }^{1}$ Dominick P. Purpura Department of Neuroscience, Albert Einstein College of Medicine, Bronx, NY 10461

${ }^{2}$ Department of Psychiatry and Behavioral Sciences, Albert Einstein College of Medicine,

11 Bronx, NY 10461.

$12{ }^{3}$ Current address: Center for Neural Science and Medicine, Cedars-Sinai Medical Center, Los

13 Angeles, CA 90048

"Equal contribution

Author Contributions: SM, SL, PJL and PEC designed the experiments. SM, SL and PJL performed experiments and analyzed data. DLH performed preliminary experiments and made observations that triggered this study. SM and PEC wrote the first manuscript which was edited by all authors.

${ }^{*}$ Correspondence should be addressed to:

Pablo E. Castillo, M.D., Ph.D.

Dominick P. Purpura Department of Neuroscience

Albert Einstein College of Medicine

Rose F. Kennedy Center, Room 703

1410 Pelham Parkway South

Bronx, NY 10461

Phone: 718.430 .3262

E-mail: pablo.castillo@einsteinmed.org

Number of Figures: 6

Number of Tables: none

Number of Multimedia: none

Number of Extended Figures: 2
Number of words for Abstract: 177

Number of words for Significant Statement: 119

Number of words for Introduction: 388

Number of words for Discussion: 1334

Funding sources: This work supported by the NIH (F32-NS077696 to S.M.; R01-DA17392, R01

Acknowledgements:

We thank all the Castillo lab members for invaluable discussions. We also thank Professor

Peter Jonas for his insightful comments on a recent version of our manuscript.

Conflict of Interest: There are no conflicts of interest to report. 


\section{ABSTRACT}

2 In the hippocampus, the excitatory synapse between dentate granule cell axons - or mossy

3 fibers (MF) - and CA3 pyramidal cells (MF-CA3) expresses robust forms of short-term plasticity,

4 such as frequency facilitation and post-tetanic potentiation (PTP). These forms of plasticity are

5 due to increases in neurotransmitter release, and can be engaged when dentate granule cells

6 fire in bursts (e.g. during exploratory behaviors) and bring CA3 pyramidal neurons above

7 threshold. While frequency facilitation at this synapse is limited by endogenous activation of

8 presynaptic metabotropic glutamate receptors, whether MF-PTP can be regulated in an activity-

9 dependent manner is unknown. Here, using physiologically relevant patterns of mossy fiber

10 stimulation in acute mouse hippocampal slices, we found that disrupting postsynaptic $\mathrm{Ca}^{2+}$

11 dynamics increases MF-PTP, strongly suggesting a form of $\mathrm{Ca}^{2+}$-dependent retrograde

12 suppression of this form of plasticity. PTP suppression requires a few seconds of MF bursting

13 activity and $\mathrm{Ca}^{2+}$ release from internal stores. Our findings raise the possibility that the powerful

14 MF-CA3 synapse can negatively regulate its own strength not only during PTP-inducing activity

15 typical of normal exploratory behaviors, but also during epileptic activity.

\section{SIGNIFICANCE STATEMENT}

18 The powerful mossy fiber-CA3 synapse exhibits strong forms of plasticity that are engaged

19 during location-specific exploration, when dentate granule cells fire in bursts. While this synapse

20 is well-known for its presynaptically-expressed LTP and LTD, much less is known about the

21 robust changes that occur on a shorter time scale. How such short-term plasticity is regulated,

22 in particular, remains poorly understood. Unexpectedly, an in vivo-like pattern of presynaptic

23 activity induced robust post-tetanic potentiation (PTP) only when the postsynaptic cell was

24 loaded with a high concentration of $\mathrm{Ca}^{2+}$ buffer, indicating a form of $\mathrm{Ca}^{2+}$-dependent retrograde

25 suppression of PTP. Such suppression may have profound implications for how environmental

26 cues are encoded into neural assemblies, and for limiting network hyperexcitability during

27 seizures. 


\section{INTRODUCTION}

3 Mossy fibers (MFs), the axonal projections of dentate granule cells (GC), provide a strong 4 excitatory input onto hippocampal CA3 pyramidal neurons (Henze et al., 2000; Nicoll and 5 Schmitz, 2005). The MF-CA3 synapse is well known for exhibiting uniquely strong forms of

6 short-term potentiation, including paired-pulse facilitation (PPF) and frequency facilitation, which

7 last milliseconds to seconds (Salin et al., 1996). More intense periods of high-frequency

8 stimulation typically elicit post-tetanic potentiation (e.g. MF-PTP), which decays over several

9 minutes (Griffith, 1990). These forms of plasticity are commonly attributed to an increase in

10 presynaptic release probability (Pr) (Zucker and Regehr, 2002; Nicoll and Schmitz, 2005;

11 Regehr, 2012), a change in the readily releasable pool (Vandael et al., 2020), and transiently

12 convert the synapse from a high- to lower-pass filter (Abbott and Regehr, 2004). In behaving

13 rodents, during place field activation, GCs can fire in high-frequency bursts (Pernia-Andrade

14 and Jonas, 2014; Diamantaki et al., 2016; GoodSmith et al., 2017; Senzai and Buzsaki, 2017),

15 driving CA3 pyramidal neurons above threshold (Henze et al., 2002). Thus, frequency

16 facilitation and MF-PTP could have a profound impact on how memory traces are encoded into

17 CA3 neural ensembles.

19 Given the apparent ease with which these robust forms of presynaptic potentiation are elicited

20 at the MF-CA3 synapse, one might expect a process by which the connection is negatively

21 regulated. In fact, there is evidence that endogenously released glutamate transiently

22 suppresses frequency facilitation via presynaptic group II metabotropic glutamate receptors (II-

23 mGluRs) (Scanziani et al., 1997; Toth et al., 2000; Kwon and Castillo, 2008a). It is unknown,

24 however, whether forms of longer-lasting plasticity, such as MF-PTP, are also curtailed in an 25 activity-dependent manner. 
1 In the present study we performed whole-cell recordings from CA3 pyramidal neurons in mouse

2 hippocampal slices and mimicked physiologically-relevant activity patterns by stimulating GCs

3 with a brief, high-frequency bursting paradigm. To our surprise, MF-PTP was readily observed

4 when the postsynaptic cell was dialyzed with a solution containing high $\mathrm{Ca}^{2+}$ buffering

5 properties, but was nearly absent when the recording solution had a lower, more physiological

$6 \mathrm{Ca}^{2+}$ buffering capacity. These findings strongly suggest that MF-PTP is normally suppressed by

7 a $\mathrm{Ca}^{2+}$-dependent retrograde mechanism. Such negative feedback could not only enable

8 homeostatic regulation of MF-CA3 synaptic strength, ensuring that the essential filtering

9 properties of the connection are maintained during ongoing activity, but also prevent runaway

10 network excitability, as may occur during epileptic activity.

\section{METHODS}

\section{Slice Preparation}

15 Animal procedures were approved by our Institutional Animal Care and Use Committee and 16 adhered to National Institutes of Health guidelines. C57BL mice (18-28 days old) were deeply 17 anesthetized with isoflurane, decapitated, and brains rapidly removed and both hippocampi 18 were dissected. Transverse hippocampal slices $(400 \mu \mathrm{m})$ were cut on a DTK-2000 microslicer

19 (Dosaka, Kyoto, Japan) or a Leica VT1200 S vibratome, in ice-cold cutting solution containing 20 (in mM): 215 sucrose, $2.5 \mathrm{KCl}, 20$ glucose, $26 \mathrm{NaHCO}_{3}, 1.6 \mathrm{NaH}_{2} \mathrm{PO}_{4}, 1 \mathrm{CaCl}_{2}, 4 \mathrm{MgSO}_{4}$, and 4 $21 \mathrm{MgCl}_{2}$. After 10 minutes of incubation at room temperature, the cutting solution was exchanged 22 for the artificial cerebrospinal fluid (ACSF) containing $124 \mathrm{NaCl}, 2.5 \mathrm{KCl}, 10$ glucose, 26 $23 \mathrm{NaHCO}_{3}, 1 \mathrm{NaH}_{2} \mathrm{PO}_{4}, 2.5 \mathrm{CaCl}_{2}$, and $1.3 \mathrm{MgSO}_{4}$. Both cutting and ACSF solutions were

24 saturated with $95 \% \mathrm{O}_{2}$ and $5 \% \mathrm{CO}_{2}(\mathrm{pH} 7.4)$. The slices recovered at room temperature for at 25 least 1.5 hour before recording. 


\section{Electrophysiology}

2 Slices were transferred to a recording chamber and perfused with ACSF (2 $\mathrm{ml} / \mathrm{min})$. Recordings

3 were done at $25^{\circ} \mathrm{C}$, except for the experiments included in Fig $\mathbf{1 a}, \mathbf{6 e}-\mathbf{h}$, and those that used

4 BoTX that were performed at $32^{\circ} \mathrm{C}$. The recording pipette was filled with an internal solution

5 containing (in mM): $112 \mathrm{~K}$-gluconate, $17 \mathrm{KCl}, 0.04 \mathrm{CaCl}_{2}, 10 \mathrm{HEPES}, 2 \mathrm{Mg}$-ATP, $0.2 \mathrm{GTP}, 10$

$6 \mathrm{NaCl}$, and 0.1 EGTA (pH 7.2) (290-295 mOsm). For the experiments using $10 \mathrm{mM}$ EGTA or

7 BAPTA, the concentration of K-gluconate was reduced to compensate for osmolarity. The

8 pipette resistance ranged from 3-4 $M \Omega$. Series resistance (6-15 $M \Omega$ ) was monitored throughout

9 the experiment, and those experiments in which the series resistance changed by more than

$1010 \%$ were not included for analysis. Patch pipettes were pulled on a PP-830 vertical puller

11 (Narishige, Tokyo, Japan).

13 Responses were generated by stimulating presynaptic axons and recording from CA3 pyramidal

14 neurons. Kainate receptor (KAR) responses were recorded in the presence of GYKI-53655 (30

$15 \mu \mathrm{M})$ or LY $303070(15 \mu \mathrm{M})$, and CGP-55845 $(3 \mu \mathrm{M})$ in the bath, and MK-801 $(2 \mathrm{mM})$ in the

16 pipette. With the exception of data obtained in Fig. 1a, Extended Fig. 5c and Fig. 6e-h, $\alpha-$

17 amino-3-hydroxy-5-methyl-4-isoxazole propionic acid receptor (AMPAR)-mediated responses

18 were also generated with MK-801 in the pipette, and GYKI-53655 (1 $\mu \mathrm{M})$ in the bath (Kwon and

19 Castillo, 2008a). N-methyl-D-aspartate receptor (NMDAR) responses were recorded with NBQX

$20(10 \mu \mathrm{M})$ in the bath. All experiments except those in Fig. 1a,c and Fig. 6e-h contained

21 picrotoxin $(100 \mu \mathrm{M})$.

23 KAR and NMDAR-mediated EPSCs were evoked by placing a monopolar stimulating pipette

24 with a broken tip ( 5-10 $\mu$ m diameter, filled with ACSF) in the dentate gyrus (DG) cell body

25 layer. For AMPAR-mediated responses, the tip was left unbroken $(\sim 1 \mu \mathrm{m})$ to minimize the

26 number of MFs activated. For minimal stimulation experiments, a theta-glass stimulating pipette 
1 was placed in stratum lucidum $100 \mu \mathrm{m}$ apart from the recorded CA3 pyramidal cell. Intensity

2 was increased until a success/failure pattern of AMPAR-EPSC responses was observed. MF

3 AMPAR-EPSCs were only accepted for analysis if the following criteria were met: robust PPF

4 (at least 2 fold), DCG-IV sensitivity $>$ than $85 \%$, fast rise time $(10-90 \%)$ was $<1.2 \mathrm{~ms}$, response

5 onset was $<5.0 \mathrm{~ms}$, and these values did not significantly change after the bursting. These

6 criteria were based on those established by previous studies of MF-CA3 transmission (Jonas et

7 al., 1993). To record KAR- and AMPAR-EPSCs, cells were voltage-clamped at $-60 \mathrm{mV}$. For

8 NMDAR-EPSCs, cells were held at $-50 \mathrm{mV}$. Unless otherwise stated, baseline NMDAR- and

9 KAR-EPSCs were obtained by delivering two stimuli separated by $5 \mathrm{~ms}$ in order to evoke a

10 measurable response (Weisskopf and Nicoll, 1995). Stimulus intensity for KAR/NMDAR- and

11 AMPAR-mediated responses was approximately 100 and $10 \mu A$, respectively. Stimulus

12 intensities did not differ, on average, between control and BAPTA-dialyzed cells in any given

13 condition. Stimulus duration was $100-200 \mu s$. CA3 neurons were always dialyzed for $\geq 15$ min,

14 while stimulating at $0.1 \mathrm{~Hz}$, before delivering any plasticity-inducing stimulation. For synaptically-

15 evoked action potentials (Fig. 6e-h), no drugs were bath applied and CA3 pyramidal cells were

16 held in current-clamp mode before, during and after the induction. Resting potential was kept

17 between -70 and $-75 \mathrm{mV}$. Baseline and post-induction spiking probability were measured as the

18 average of number of spikes per burst normalized to the number of pulses per burst. (i.e. 3

19 pulses at $25 \mathrm{~Hz}$ ).

21 The baseline stimulation frequency for all experiments was $0.1 \mathrm{~Hz}$, except for frequency

22 facilitation (5 stimuli, $25 \mathrm{~Hz}$ ), which was delivered at $0.05 \mathrm{~Hz}$. The standard PTP induction

23 protocol consisted of 25 bursts $(5$ stimuli, $50 \mathrm{~Hz}$ ) delivered at $2 \mathrm{~Hz}$. PTP was never generated

24 more than once in a given slice. To achieve a similar time course of potentiation in BAPTA-

25 dialyzed cells when the inter-stimulus interval was $40 \mathrm{~ms}$ (Fig. 3c), or when monitoring MF

26 AMPAR-mediated transmission (Figs. 1a, 3b), it was necessary to use 50 bursts. The bursting 
1 protocol was delivered while cells were voltage-clamped at $-60 \mathrm{mV}$, except for one experiment

2 in which the induction was performed in current-clamp (Fig. 1a,c and Fig. 6e-h). Long-term

3 potentiation (LTP) in CA1 pyramidal neurons was induced by pairing postsynaptic depolarization

4 from $-60 \mathrm{mV}$ to $0 \mathrm{mV}$ for $3 \mathrm{~min}$ with low-frequency stimulation of Schaffer collaterals (180

5 pulses, $2 \mathrm{~Hz})$.

7 In all experiments examining MF synaptic transmission, the mGluR2/3 agonist DCG-IV (1-2 $\mu \mathrm{M})$

8 was applied at the end of the experiment and data were included only when the response was

9 inhibited by more than $85 \%$. For perforated patch experiments, nystatin was first dissolved into

10 DMSO $(10 \mathrm{mg} / \mathrm{mL})$. This was then diluted 250 -fold into the intracellular solution to yield 40

$11 \mu \mathrm{g} / \mathrm{mL}$. Botulinum toxin-B (BoTX) was prepared by making a $0.5 \mu \mathrm{M}$ stock solution with 1

$12 \mathrm{mg} / \mathrm{mL}$ BSA. This was then diluted 100-fold into the final intracellular solution, with $0.5 \mathrm{mM} \mathrm{DL-}$

13 Dithiothreitol (DTT).

\section{Reagents}

16 MK-801, NBQX, CGP-55845, Nimodipine, AM-251, DCG-IV, and GYKI 53655 were obtained

17 from Tocris-Cookson (Minneapolis, MN, USA). LY 303070 was obtained from ABX advanced

18 biochemical compounds (Radeberg, Germany). BoTX was obtained from List Biological

19 (Cambell, CA, USA). All other chemicals and drugs were purchased from Sigma-Aldrich (St.

20 Louis, MO, USA).

\section{Data Analysis}

23 Experiments were executed with a MultiClamp 700B amplifier (Molecular Devices, Union City,

24 CA, USA). Data were analyzed online using IgorPro (Wavemetrics, Lake Oswego, OR, USA), 25 and offline with Origin 9.2 (Northampton, MA, USA) and GraphPad Prism (La Jolla, CA, USA).

26 The three minutes before the induction protocol was used as a baseline for statistics. Following 
1 the protocol, the first three minutes were used to calculate PTP, and the last three minutes (of a

230 minute period) for the positive control experiment testing LTP at the Schaffer collateral to

3 CA1 pyramidal cell synapse (Extended Fig. 5c). Representative responses are averages of 18

4 traces. All values are shown as mean \pm SEM. Unless otherwise stated, Student's t-test was

5 used for statistical significance between two samples, and ANOVA for multiple comparisons.

6 Data that did not display a normal distribution were compared using the non-parametric test

7 Mann-Whitney. All experiments for a given condition were performed in an interleaved fashion -

8 i.e. control experiments were performed for every test experiment.

\section{RESULTS}

Mossy fiber post-tetanic potentiation is minimal under physiological postsynaptic $\mathrm{Ca}^{2+}$ buffering conditions

16 This study was initiated by the unexpected observation that MF-PTP magnitude was highly

17 dependent on the postsynaptic $\mathrm{Ca}^{2+}$ buffering conditions. We induced MF-PTP by activating

18 MFs with a bursting protocol (25 bursts delivered at $2 \mathrm{~Hz} ; 5$ stimuli at $50 \mathrm{~Hz}$ within a burst)

19 designed to mimic physiological activity patterns of GCs in vivo (Henze et al., 2002; Pernia-

20 Andrade and Jonas, 2014; Diamantaki et al., 2016; GoodSmith et al., 2017; Senzai and

21 Buzsaki, 2017), while monitoring AMPAR-EPSCs (see Methods) under physiological recording

22 conditions -e.g. no drugs in the bath, near-physiological recording temperature $\left(32^{\circ} \mathrm{C}\right)$ and

23 voltage clamping at resting membrane potential (chloride reversal potential). The PTP induction

24 protocol was delivered in current-clamp configuration so that CA3 cells were able to fire freely.

25 To our surprise, we did not observe much potentiation when postsynaptic CA3 pyramidal cells

26 were loaded with $0.1 \mathrm{mM}$ EGTA, a near physiological intracellular $\mathrm{Ca}^{2+}$ buffering condition that 
1 we refer as "control", but saw robust MF-PTP with 10 mM BAPTA in the postsynaptic pipette

2 (Fig. 1a). In contrast, BAPTA did not increase PTP of associational-commissural (AC) synaptic

3 responses (Fig. 1b). These results are consistent with previous studies that reported little

4 potentiation at the AC synapse (Salin et al., 1996), and suggest that the robust PTP unmasked

5 in BAPTA-dialyzed cells is specific to the MF-CA3 synapse. Importantly, the enhancement of

6 MF-PTP under high postsynaptic $\mathrm{Ca}^{2+}$ buffering conditions was also observed with minimal

7 stimulation of MFs (Jonas et al., 1993) (Fig. 1c), indicating that the PTP enhancement is not an

8 artifact due to strong extracellular stimulation. Lastly, we found that $10 \mathrm{mM}$ BAPTA did not affect

9 the basal paired-pulse ratio (PPR) (i.e. prior to bursting) (Fig. 1d), making unlikely that changes

10 in basal Pr could account for the PTP enhancement. These initial observations suggested that

11 MF-PTP, a phenomenon widely believed to be presynaptic in nature, was under the control of a

12 postsynaptic $\mathrm{Ca}^{2+}$-dependent process that deserved further investigation.

14 A major problem when studying MF-CA3 synaptic plasticity is the polysynaptic contamination

15 associated with extracellular stimulation of MFs (Claiborne et al., 1993; Henze et al., 2000;

16 Nicoll and Schmitz, 2005; Kwon and Castillo, 2008a). Repetitive stimulation aggravates this

17 problem as MF-CA3 synapses can be potentiated several-fold by strong frequency facilitation

18 (Regehr et al., 1994; Salin et al., 1996). To rule out the possibility that the PTP was the result of

19 polysynaptic contamination, we blocked AMPA and NMDA receptor-mediated transmission, and

20 monitored kainate receptor-EPSCs (KAR-EPSCs), which are observed at MF-CA3 synapses but

21 not AC-CA3 synapses (Castillo et al., 1997). When CA3 pyramidal neurons were loaded with 10

22 mM BAPTA the burst stimulation protocol caused a robust PTP of KAR-mediated transmission

23 as compared to control (0.1 mM EGTA) (Fig. 2a). To discard that PTP suppression could be

24 due to some unexpected effect of BAPTA, we repeated our experiments with 10 mM EGTA, a

25 slow $\mathrm{Ca}^{2+}$ chelator that is widely used at this concentration in voltage-clamp recordings. MF-

26 PTP was equally robust in 10 mM EGTA-loaded cells (Fig. 2b, Extended Fig. 2). To ensure 
1 fast postsynaptic $\mathrm{Ca}^{2+}$ chelation, subsequent experiments compared cells loaded with $0.1 \mathrm{mM}$

2 EGTA vs. $10 \mathrm{mM}$ BAPTA. Collectively, these findings demonstrate that postsynaptic $\mathrm{Ca}^{2+}$

3 buffering had a striking influence on the magnitude of MF-PTP.

5 One interpretation of the set of observations above is that CA3 pyramidal neurons normally

6 have high $\mathrm{Ca}^{2+}$ buffering capacity (i.e. similar to $10 \mathrm{mM} \mathrm{EGTA}$ ), and replacing these with the 0.1

7 mM EGTA solution somehow abolished PTP. To directly address this possibility, we monitored

8 KAR-EPSPs with BAPTA in the recording pipette, in perforated patch vs. whole-cell

9 configuration. In perforated patch conditions, in which BAPTA could not diffuse into the cell, only

10 a small amount of PTP was seen, while KAR-EPSPs in whole-cell mode displayed similar

11 striking potentiation observed above when KAR-EPSCs were recorded from BAPTA-loaded

12 cells (Fig. 2c, see also Fig. 2a). These results indicate that the endogenous $\mathrm{Ca}^{2+}$ buffering

13 capacity of CA3 pyramidal neurons was functionally more similar to the $0.1 \mathrm{mM}$ EGTA solution

14 than to the $10 \mathrm{mM}$ BAPTA solution.

16 We next confirmed the presynaptic nature of MF-PTP in BAPTA conditions. If this PTP was

17 presynaptic, it should be similarly observed when monitoring KAR-EPSCs, NMDAR-EPSCs and

18 AMPAR-EPSCs (unlike the data reported in Fig. 1a, AMPAR-EPSCs in these experiments were

19 pharmacologically isolated and recorded under conditions of low network excitability; see

20 Methods). Indeed, when either NMDAR- or AMPAR-mediated EPSCs were monitored, little to

21 no potentiation was observed in control conditions, but the response was markedly increased in

22 BAPTA (Fig. 3a,b). Notably, there was no difference when comparing the PTP magnitude of

23 control cells in KA, AMPA, and NMDA receptor groups to each other (ANOVA; F=1.76; $p>0.2$,

$24 \mathrm{DF}=15)$, or when comparing the BAPTA-dialyzed cells in the three receptor groups to each

25 other (ANOVA; $F=0.74 ; p>0.4, D F=17$ ). Thus, the difference in PTP between control and

26 BAPTA persisted regardless of which postsynaptic receptor was pharmacologically isolated. To 
1 assess changes in PPR, we monitored KAR-mediated responses. Here, the induction was

2 accompanied by a greater reduction in PPR in BAPTA-dialyzed cells, consistent with an

3 increase in Pr. Importantly, in both control and BAPTA-dialyzed cells, the recovery time course

4 of EPSC amplitude and PPR mirrored each other (Fig. 3c), suggestive of a causal relationship

5 between presynaptic $\operatorname{Pr}$ and the postsynaptic response magnitude. Together, these

6 independent lines of evidence confirm a presynaptic locus of MF-PTP in BAPTA-dialyzed cells.

7 Again, as for AMPAR-EPSCs (Fig. 1d), no significant difference was noted in the degree of

8 basal PPR (i.e. before bursting) between control and BAPTA-dialyzed cells (Control: $2.4 \pm 0.2$;

$9 n=25 ;$ BAPTA $2.7 \pm 0.2 ; n=27$; Control vs. BAPTA $p>0.2$; data not shown), supporting the notion

10 that postsynaptic BAPTA loading did not affect basal Pr. The most parsimonious explanation for

11 a robust presynaptic potentiation being unmasked by preventing a rise in postsynaptic $\mathrm{Ca}^{2+}$ is a

12 retrograde signal that suppresses potentiation in normal conditions. This interpretation is

13 consistent with the fact that most forms of retrograde signaling so far described require a rise in

14 postsynaptic $\mathrm{Ca}^{2+}$ concentration (Fitzsimonds and Poo, 1998; Regehr et al., 2009).

\section{Source of postsynaptic $\mathrm{Ca}^{2+}$ rise involved in PTP suppression}

17 We next sought to assess the source or sources of the postsynaptic $\mathrm{Ca}^{2+}$ rise involved in the 18 suppression of MF-PTP. $\mathrm{Ca}^{2+}$ influx via NMDARs, or $\mathrm{Ca}^{2+}$-permeable AMPARs or KARs, was 19 ruled out as solely sufficient for retrograde suppression, given that pharmacological blockade of

20 these receptors did not unmask PTP (Figs. 2, 3a). Several voltage-gated $\mathrm{Ca}^{2+}$ channels

21 (VGCCs) exist in the thorny excrescence of CA3 pyramidal neurons (Kapur et al., 2001; Reid et

22 al., 2001). Since the thorny excrescences in our experiments could have been poorly voltage-

23 clamped (at $-60 \mathrm{mV}$ ) during the induction protocol, one or more of these channels may have

24 contributed to the rise in postsynaptic $\mathrm{Ca}^{2+}$. To address this possibility, we clamped CA3

25 neurons at $-80 \mathrm{mV}$, a voltage at which all VGCCs should be closed. L-type channels mediate a

$26 \mathrm{Ca}^{2+}$ rise induced by MF burs stimulation (Kapur et al., 2001). We therefore also added 
1 nifedipine $(25 \mu \mathrm{M})$ to the bath solution to ensure L-type VGCCs were blocked in this experiment.

2 If L-type channels were in fact the source of the $\mathrm{Ca}^{2+}$ required for the putative retrograde

3 suppression, we would expect that blocking those channels would mimic the effect of BAPTA,

4 and that both control and BAPTA-dialyzed cells exhibit robust PTP. However, under these

5 recording conditions, a large difference between control and BAPTA-dialyzed cells remained

6 (Fig. 4a), suggesting that L-type channels do not contribute significantly to the regulation of MF-

7 PTP. We next examined the potential role of R-type and T-type VGCCs by adding $100 \mu \mathrm{M} \mathrm{Ni}^{2+}$

8 while blocking L-type VGCCs with $10 \mu \mathrm{M}$ nimodipine. Under these recording conditions, and

9 likely due to the blockade of presynaptic R-type channels, as previously reported (Breustedt et

10 al., 2003; Dietrich et al., 2003), MF-PTP was dampened, but the difference between low and

11 high postsynaptic $\mathrm{Ca}^{2+}$ buffering conditions remained (Fig. 4b). It is therefore unlikely that R-

12 type and T-type VGCCs in CA3 pyramidal neurons contribute significantly to the regulation of

13 MF-PTP under physiological intracellular $\mathrm{Ca}^{2+}$ buffer conditions.

15 To investigate the potential role of intracellular $\mathrm{Ca}^{2+}$ stores, we included cyclopiazonic acid 16 (CPA) $(30 \mu \mathrm{M})$ in the patch pipette to deplete $\mathrm{Ca}^{2+}$ from the endoplasmic reticulum. CPA led to 17 an increase in MF-PTP relative to control cells (Fig. 4c), suggesting that the rise in $\mathrm{Ca}^{2+}$ 18 required by the retrograde signal is mediated, at least partially, by intracellular stores. CPA 19 could have diffused from the recorded cell to the presynaptic terminal, reduced Pr, and thereby 20 increased the magnitude of PTP. To address this possibility, we delivered a synaptic burst (5 21 pulses, $25 \mathrm{~Hz}$ ) to cells loaded with control solution, and those loaded with CPA. There was no 22 difference between the ratio of the fifth/first KAR-EPSC amplitude (control: $7.5 \pm 1.7$; $n=5$; CPA:

$236.9 \pm 1.2 ; n=5 ; p>0.5$; data not shown), suggesting no difference in Pr. Thus, the increase in

24 PTP seen in CPA-loaded cells was likely due to depletion of postsynaptic $\mathrm{Ca}^{2+}$ stores. Lastly,

25 release of $\mathrm{Ca}^{2+}$ from internal stores can be triggered by activation of inositol 1,4,5-trisphosphate 26 receptors (IP3Rs)(Verkhratsky, 2005), a signaling pathway that has been shown to underlie 
$1 \mathrm{Ca}^{2+}$ rises in CA3 pyramidal neurons (Kapur et al., 2001) and postsynaptic plasticity (Kwon and

2 Castillo, 2008b) at the MF-CA3 synapse. To examine whether IP3Rs played a role in the

3 suppression of MF-PTP, we included heparin $(2.5 \mathrm{mg} / \mathrm{mL})$ in the patch pipette. With IP3Rs

4 blocked, PTP was increased to a similar level as when cells were loaded with CPA (Fig. 4d).

5 Together, these results suggest that IP3R-triggered release from internal $\mathrm{Ca}^{2+}$ stores

6 contributes to the suppressive effect on PTP.

8 Assessing the mechanism underlying MF-PTP suppression

9 One way that the release of $\mathrm{Ca}^{2+}$ from internal stores can be triggered is via activation of group I

10 mGluRs (i.e. mGluR1 and mGluR5 subtypes). These G-protein-coupled receptors (GPCRs) are

11 likely activated during our PTP induction protocol and have been shown to mobilize $\mathrm{Ca}^{2+}$ stores

12 at the MF-CA3 synapse (Kapur et al., 2001). However, with the mGluR5 antagonist MPEP (4

$13 \mu \mathrm{M})$ and the mGluR1 antagonist CPCCOEt $(100 \mu \mathrm{M})$ in the bath solution, a large difference

14 remained between the potentiation observed in control and BAPTA-dialyzed cells (Fig. 5a),

15 whereas in separate experiments we found these antagonists greatly reduced the inward

16 current induced by the group I mGluR agonist DHPG (Extended Fig. 5a). To test for the

17 potential involvement of other GPCRs in mobilizing $\mathrm{Ca}^{2+}$ from internal stores (e.g. by activating

18 IP3Rs), we used GDP- $\beta S$ (1 mM), a nonhydrolyzable GDP analog that interferes with G-protein

19 signaling. Including GDP- $\beta S$ in the recording pipette solution had no apparent effect on the

20 retrograde suppression as we observed significantly less MF-PTP in control compared to

21 BAPTA-dialyzed cells (Fig. 5b). As positive control, we found that intracellularly loaded GDP- $\beta S$

22 in CA3 pyramidal neurons abolished the outward current induced by the GABA $A_{B}$ agonist

23 baclofen $(50 \mu \mathrm{M})$ (Extended Fig. 5b). Altogether, these results suggest that mobilization of the

24 putative retrograde signal that suppresses MF-PTP requires IP3R-mediated release of $\mathrm{Ca}^{2+}$

25 from internal stores, but is independent from the activation of Group I mGluRs or other GPCR- 
1 dependent signaling, although we cannot rule out the possibility that $G$ protein-independent

2 signaling could be involved (Gerber et al., 2007).

4 Dendrites on postsynaptic neurons have been shown to release retrograde messengers

5 consisting of lipids, gases, peptides, growth factors, and conventional neurotransmitters

6 (Regehr et al., 2009), some of which are released by SNARE-dependent exocytosis. To test

7 whether the putative retrograde signaling suppressing MF-PTP involves vesicular release, we

8 used botulinum toxin-B (BoTX), which cleaves synaptobrevin-2, thus eliminating SNARE-

9 dependent exocytosis (Schiavo et al., 2000; Montal, 2010). Adding BoTX (5 nM) to the

10 intracellular solution did not enhance MF-PTP (Fig. 5c). In separate, interleaved experiments

11 that served as a positive control, and as previously reported (Lledo et al., 1998), we found that

12 loading BoTx into CA1 pyramidal neurons blocked LTP of AMPAR-mediated transmission (see

13 Methods) (Extended Fig. 5c). These findings argue against SNARE-dependent exocytosis in

14 mediating the putative retrograde signal involved in MF-PTP suppression.

16 We next examined whether lipids mediate MF-PTP suppression. For instance,

17 endocannabinoids, perhaps the most characterized retrograde signals in the brain (Kano et al.,

18 2009; Castillo et al., 2012), suppress PTP at the parallel fiber-Purkinje cell synapse in the

19 cerebellum by activating presynaptic type 1 cannabinoid receptors (Beierlein et al., 2007).

20 However, these receptors are not expressed at the MF-CA3 synapse in mature animals

21 (Marsicano and Lutz, 1999; Katona et al., 2006; Hofmann et al., 2008; Caiati et al., 2012). To

22 test whether a different lipid signal acting as a retrograde signal, such as arachidonic acid (AA)

23 (Carta et al., 2014), or the AA metabolite 12-(S)-HPETE (Feinmark et al., 2003), could suppress

24 MF-PTP, we added a cocktail of inhibitors to the patch pipette solution in order to inhibit AA and

25 other components of lipid synthesis in the postsynaptic neuron. We included eicosatetraynoic

26 acid (ETYA; $100 \mu \mathrm{M})$ and indomethacin $(10 \mu \mathrm{M})$ to inhibit lipoxygenases and cyclooxygenases 
1 (COX 1 and 2), enzymes that catalyze the metabolism of eicosanoids and prostanoids,

2 respectively. We also added $\mathrm{RHC}-80267(50 \mu \mathrm{M})$ to inhibit diacylglycerol (DAG) lipase. With this

3 combination of lipid inhibitors in the pipette, we continued to see robust MF-PTP in BAPTA-

4 dialyzed cells, but none when the cocktail was included in control cells (Fig. 5d). Our results

5 suggest that the putative retrograde signal that suppressed PTP at the MF-CA3 synapse does

6 not depend on these lipid-derived pathways.

8 Lastly, we explored potential ways by which glutamate release was suppressed during PTP.

9 Presynaptic type 1 adenosine receptors (A1Rs) can tonically inhibit glutamate release at this

10 synapse (Moore et al., 2003) (but see Kukley et al., 2005). To test whether these receptors

11 mediate MF-PTP suppression, we used the A1R-selective antagonist DPCPX (200 nM). DPCPX

12 did not alter the robust difference in PTP observed in control vs. BAPTA-dialyzed cells (Fig. 5e),

13 but significantly increased the amplitude of MF KAR-EPSCs (Extended Fig. 5d), indicating that

14 DPCPX was active and therefore, A1Rs were not underlying the suppression of MF-PTP.

15 Glutamate release from MFs is also blocked by the activation of presynaptic group II/III mGluRs

16 (Kamiya et al., 1996). While our results using BoTX make it unlikely that these receptors were

17 targeted by glutamate released from the postsynaptic cell, glutamate could have been

18 generated from other sources (e.g. glia). However, in the presence of the group II and III mGluR

19 antagonists LY $341495(1 \mu \mathrm{M})$ and MSOP $(200 \mu \mathrm{M})$, respectively, the large difference between

20 control and BAPTA remained (Fig. 5f). These antagonists almost completely reverse the DCG-

21 IV-mediated suppression of MF transmission (Extended Fig. 5e). It is therefore unlikely that

22 activation of presynaptic mGluR2/3 underlies the suppression of MF-PTP.

\section{Strong presynaptic activity is required for retrograde suppression of glutamate release}

25 The types of activity under which retrograde suppression of transmitter release manifests could 26 have important implications for the CA3 network. We found that burst-induced facilitation, 
1 measured by the ratio of the fifth KAR-EPSC amplitude to that of the first (P5/P1) in a single

2 burst (five pulses, $25 \mathrm{~Hz}$ ), was not significantly different in control vs BAPTA conditions (Fig.

3 6a). We also examined the effect of postsynaptic $\mathrm{Ca}^{2+}$ buffering on low-frequency facilitation

4 (LFF), whereby single KAR-EPSCs were evoked, first during $0.1 \mathrm{~Hz}$ basal stimulation, and after

5 switching to $1 \mathrm{~Hz}$. No difference was observed between conditions (Fig. 6b). Thus, for these

6 modest increases in activity, postsynaptic $\mathrm{Ca}^{2+}$ buffering seemed to have no impact on

7 presynaptic transmitter release. Moreover, because frequency facilitation is highly dependent on

8 the starting $\operatorname{Pr}$ (Zucker and Regehr, 2002; Nicoll and Schmitz, 2005; Regehr, 2012), these

9 results argue against a tonic suppression of neurotransmitter release under high postsynaptic

$10 \quad \mathrm{Ca}^{2+}$ buffering conditions.

12 We next delivered multiple bursts in order to determine how strong the bursting paradigm must

13 be before retrograde suppression of MF-PTP is observed. To this end, we increased the

14 number of bursts while maintaining both the frequency within a burst $(50 \mathrm{~Hz})$, as well as

15 between bursts $(2 \mathrm{~Hz})$. After three bursts, synaptic responses were similar in both $\mathrm{Ca}^{2+}$ buffering

16 conditions (i.e. control and BAPTA), but a difference emerged after 10 bursts (Fig. 6c), and a

17 larger difference was also seen after increasing the number of bursts to 50 . In BAPTA-dialyzed

18 cells, there was a difference between 3 vs.10 (ANOVA, F=21.9; $p<0.05 ; D F=10$ ), 3 vs. 25

$19(p<0.001, D F=10), 3$ vs. 50 ( $p<0.001, D F=9), 10$ vs. $50(p<0.001, D F=11)$, and 25 vs. 50 bursts

$20(p<0.05, D F=11)$. Together these data not only uncover the magnitude of MF-PTP in the

21 absence of a retrograde suppressive signal, but also show that in our BAPTA conditions, a

22 longer bursting paradigm induces stronger MF-PTP. The threshold observed with 10 bursts is

23 relatively modest, highlighting that this form of regulation could likely manifest in vivo.

25 We next examined whether stronger activation of MFs could overcome the suppressive 26 retrograde signal. To address this possibility we delivered high-frequency stimulation (HFS) 
1 consisting of three trains of 100 stimuli $(100 \mathrm{~Hz}$ within a train; trains separated by 10 seconds).

2 While a sizeable potentiation was elicited in control cells, the magnitude of MF-PTP was

3 significantly larger in conditions of high $\mathrm{Ca}^{2+}$ buffering (Fig. $6 \mathrm{~d}$ ). Thus, the putative retrograde

4 signal is strong enough to dampen the PTP evoked even by prolonged high-frequency tetanus.

6 It has been suggested that the MF-CA3 synapse can operate as a conditional detonator (Treves

7 and Rolls, 1992; Urban et al., 2001; Henze et al., 2002), and a recent study demonstrated that

8 MF-PTP could convert MF-CA3 synapses into full detonators (Vyleta et al., 2016). However,

9 recordings in this study -like many other voltage-clamp studies- were performed under high

10 postsynaptic $\mathrm{Ca}^{2+}$ buffering conditions, i.e. $10 \mathrm{mM}$ EGTA in the recording pipette. We therefore

11 reassessed the role of PTP in MF detonation using physiological intracellular $\mathrm{Ca}^{2+}$ buffering. To

12 this end, we tested whether PTP induction facilitated the ability of a short MF burst (3 stim, 25

$13 \mathrm{~Hz}$ ) to generate action potentials in the postsynaptic CA3 pyramidal neurons loaded with either

$140.1 \mathrm{mM}$ EGTA (control) or $10 \mathrm{mM}$ BAPTA. Eliciting action potentials in BAPTA neurons was

15 easier than in control neurons, which could be due to changes in excitability (Nelson et al.,

16 2003; Roussel et al., 2006). We found that the spike probability 3 min post-PTP was significantly

17 enhanced in BAPTA but not control cells (Fig. 6e-h). These results indicate that the contribution

18 of PTP to MF detonation can be overestimated under high postsynaptic $\mathrm{Ca}^{2+}$ buffer recording

19 conditions.

\section{DISCUSSION}

23 We report here that the $\mathrm{Ca}^{2+}$ buffering capacity of the postsynaptic neuron can significantly

24 impact presynaptically-expressed PTP at the hippocampal MF-CA3 synapse. Under normal

$25 \mathrm{Ca}^{2+}$ buffering capacity, as observed during non-invasive recording conditions (e.g. perforated

26 patch recording) that do not significantly alter the physiological intracellular milieu, we found that 
1 a bursting induction protocol designed to mimic in vivo activity patterns of GCs triggered a

2 remarkably weak PTP. However, a far greater potentiation was revealed under high

3 postsynaptic $\mathrm{Ca}^{2+}$ buffering conditions. Remarkably, increasing the postsynaptic buffer capacity

4 had no significant effect on the basal Pr, arguing against a tonic suppression of neurotransmitter

5 release. The most parsimonious explanation for our findings is the presence of a $\mathrm{Ca}^{2+}-$

6 dependent, retrograde signaling mechanism that suppresses PTP. A minimum threshold was

7 required before the phenomenon was observed, above which it operated in a wide range of

8 activity. These results point to a novel, activity-dependent form of negative feedback at the MF-

9 CA3 synapse that may significantly impact DG - CA3 information transfer.

11 At first glance, our findings contrast starkly with numerous studies that have reported

12 pronounced MF-PTP (for a review see Henze et al., 2000). However, most of these studies

13 elicited MF-PTP with strong repetitive stimulation (e.g. HFS) while monitoring MF transmission

14 with extracellular field recordings. Due to activation of the CA3 network, these experimental

15 conditions not only enable the recruitment of associational-commissural inputs that are

16 commonly interpreted as MF-mediated responses, but also facilitate population spike

17 contamination of (extracellularly recorded) synaptic responses (Henze et al., 2000; Nicoll and

18 Schmitz, 2005). As a result, MF-PTP magnitude can be easily overestimated. Strong MF-PTP

19 was also observed in studies that used more sensitive, single-cell recordings (see for example

20 Zalutsky and Nicoll, 1990; Maccaferri et al., 1998; Vyleta et al., 2016; Vandael et al., 2020), but

21 here again it was typically evoked with a rather non-physiological induction protocol such as

22 HFS. Critically, many such previous studies also loaded postsynaptic neurons with $10 \mathrm{mM}$

23 EGTA, a standard concentration used in whole-cell studies, both in vitro and in vivo. Indeed, we

24 also observed striking MF-PTP in those conditions (Fig. 2b). Our findings therefore suggest that

25 MF-PTP is tightly controlled when afferent stimulation and postsynaptic $\mathrm{Ca}^{2+}$ buffering are set to

26 more physiological levels. 
2 A rise in postsynaptic $\mathrm{Ca}^{2+}$ is required for most forms of retrograde signaling (Fitzsimonds and

3 Poo, 1998; Regehr et al., 2009). Consistent with this notion, MF-PTP was suppressed when the

4 postsynaptic cell was loaded with high (milimolar) concentrations of EGTA or BAPTA, or with

5 CPA or heparin, all agents that prevent a rise in intracellular $\mathrm{Ca}^{2+}$. To determine the potential

6 source(s) of postsynaptic $\mathrm{Ca}^{2+}$ rise involved in the suppression of MF-PTP, we

7 pharmacologically interfered with these sources one by one. We found that IP3R-mediated $\mathrm{Ca}^{2+}$

8 release from intracellular stores contributed to the suppression, but that Group I mGluRs and G-

9 protein-coupled signaling alone were insufficient. Importantly, however, we cannot discard

10 synergism of multiple sources leading to the full rise in postsynaptic $\mathrm{Ca}^{2+}$ required for retrograde

11 suppression of MF-PTP, including the contribution of VGCCs in a poorly voltage-clamped

12 postsynaptic compartment (Williams and Mitchell, 2008; Beaulieu-Laroche and Harnett, 2018).

13 Interestingly, the endogenous $\mathrm{Ca}^{2+}$ buffering power of CA3 pyramidal neurons is the source of

14 some debate, as some have suggested it is higher than that of CA1 cells (Wang et al., 2004),

15 while others report it is similar (Simons et al., 2009). Further complicating this matter, different

16 endogenous buffers and extrusion mechanisms create short-lived $\mathrm{Ca}^{2+}$ nanodomains which can

17 limit the interaction between $\mathrm{Ca}^{2+}$ and its substrates (Higley and Sabatini, 2008). Our data show

18 little PTP when the intracellular composition was not perturbed in perforated patch mode, and

19 robust PTP when the cell was dialyzed with a high concentration of BAPTA (Fig. 2c). This

20 observation would indicate that, regardless the exact endogenous buffering power of these

21 cells, it is sufficiently low to allow for the postsynaptic neuron to regulate MF-PTP.

23 Retrograde signaling has been proposed to influence PTP, but typically in the opposite direction

24 to our findings. For example, in the Aplysia sensory-motor neuron preparation, injection of

25 BAPTA into the postsynaptic cell depressed PTP (Bao et al., 1997). In the hippocampus,

26 loading CA3 pyramidal neurons with high concentrations of BAPTA (30-50 mM) curtailed PTP 
1 and abolished LTP at the MF-CA3 synapse, presumably by blocking the mobilization of a

2 retrograde signal (Yeckel et al., 1999; but see Mellor and Nicoll, 2001). There is also evidence

3 that the receptor tyrosine kinase ephrin $B(E p h B)$ and its membrane-bound ligand ephrin $B$

4 mediate retrograde communication at MF-CA3 synapses, and that interfering with EphB/ephrin

5 B signaling inhibits both PTP and LTP at MF-CA3 synapses (Contractor et al., 2002; Armstrong

6 et al., 2006). Our findings resemble the endocannabinoid-mediated suppression of PTP at the

7 parallel fiber-Purkinje cell synapse via presynaptic type 1 cannabinoid receptors (Beierlein et al.,

8 2007). However, these receptors are not found at MF boutons in the mature brain (Marsicano

9 and Lutz, 1999; Katona et al., 2006; Hofmann et al., 2008; Caiati et al., 2012). While the identity

10 of the putative retrograde signal generated by the postsynaptic neuron remains unidentified,

11 some usual candidates (Regehr et al., 2009) could be discarded. Vesicular, SNARE-dependent

12 exocytosis was ruled out (Fig. 5c), indicating that the messenger is likely not a conventional

13 neurotransmitter (e.g. glutamate or GABA). Further evidence against glutamate as a retrograde

14 signaling mediating PTP suppression is the fact that this suppression remains intact after

15 blocking presynaptic group II and III mGluRs (Fig. 5f). Our findings also argue against the role

16 of another putative signal, nitric oxide (NO) given that its synthesis typically requires the

17 activation of NMDARs (Christopherson et al., 1999; Sattler et al., 1999), which were blocked in

18 most of our experiments. We cannot discard the possibility that PTP suppression involves

19 retrograde signaling via synaptic adhesion molecules. It is worth noting that identifying

20 endocannabinoids as the retrograde messengers mediating the well characterized

21 depolarization-induced suppression of inhibition (DSI) took a decade of work by several groups

22 (Barinaga, 2001). Future studies will have to determine the identity of the presumably non-

23 conventional retrograde signal and the presynaptic substrate responsible for curtailing PTP

24 (Regehr, 2012). 
1 Two recent studies suggested that MF-PTP occurs in vivo (Vandael et al., 2020) and switches

2 MF-CA3 synapses into full detonators (Vyleta et al., 2016). However, our results indicate that

3 the impact of PTP was likely overestimated because recordings in both studies were performed

4 under high, non-physiological $\mathrm{Ca}^{2+}$ buffering conditions (e.g. $10 \mathrm{mM}$ EGTA). PTP has also been

5 reported at MF to inhibitory interneuron synapses (Alle et al., 2001; Mori et al., 2007). Given that

6 MFs make 10 times as many contacts onto inhibitory interneurons as onto CA3 pyramidal cells

7 (Acsady et al., 1998), PTP at MF to interneuron synapses, by presumably activating an

8 inhibitory network, could control the activity of GCs (feed-back inhibition) and detonation of CA3

9 pyramidal neurons (feed-forward inhibition) (Lawrence and McBain, 2003). However, unlike PTP

10 at MF-CA3 synapses, postsynaptic $\mathrm{Ca}^{2+}$ buffering had no impact on PTP magnitude at MF to

11 basket cells synapses in the DG, with similarly robust PTP when the interneuron was loaded

12 with $0.1 \mathrm{mM}$ EGTA or $10 \mathrm{mM}$ BAPTA (Alle et al., 2001). Thus, although PTP is observed at

13 distinct MF synapses, the retrograde suppression we report in the present study seems to be

14 unique to the MF-CA3 pyramidal cell synapse.

16 Relatively strong GC burst activity is needed for engaging suppression of MF-PTP, and the

17 magnitude of this suppression does not seem to be overcome by stronger presynaptic activity

18 (Fig. 6c). Thus, PTP suppression may serve as a powerful mechanism of controlling DG-CA3

19 information transfer following repetitive bursts of GC activity that normally occur during

20 exploratory behaviors (Henze et al., 2002; Pernia-Andrade and Jonas, 2014; Diamantaki et al.,

21 2016; GoodSmith et al., 2017; Senzai and Buzsaki, 2017). Left unchecked, MF-PTP could

22 indirectly lead to runaway activity of the CA3 network and facilitate epileptic activity. Lastly,

23 while the generalizability of PTP suppression remains untested, future studies will be required to

24 determine whether $\mathrm{Ca}^{2+}$ indicators widely used in vitro and in vivo throughout the brain may

25 promote a similar suppression of presynaptic function. 


\section{References}

Abbott LF, Regehr WG (2004) Synaptic computation. Nature 431:796-803.

Acsady L, Kamondi A, Sik A, Freund T, Buzsaki G (1998) GABAergic cells are the major postsynaptic targets of mossy fibers in the rat hippocampus. J Neurosci 18:3386-3403.

Alle H, Jonas P, Geiger JR (2001) PTP and LTP at a hippocampal mossy fiber-interneuron synapse. Proc Natl Acad Sci U S A 98:14708-14713.

Armstrong JN, Saganich MJ, Xu NJ, Henkemeyer M, Heinemann SF, Contractor A (2006) Bephrin reverse signaling is required for NMDA-independent long-term potentiation of mossy fibers in the hippocampus. J Neurosci 26:3474-3481.

Bao JX, Kandel ER, Hawkins RD (1997) Involvement of pre- and postsynaptic mechanisms in posttetanic potentiation at Aplysia synapses. Science 275:969-973.

Barinaga M (2001) How Cannabinoids Work in the Brain. Science 291:2530-2531.

Beaulieu-Laroche L, Harnett MT (2018) Dendritic Spines Prevent Synaptic Voltage Clamp. Neuron 97:75-82 e73.

Beierlein M, Fioravante D, Regehr WG (2007) Differential expression of posttetanic potentiation and retrograde signaling mediate target-dependent short-term synaptic plasticity. Neuron 54:949-959.

Breustedt J, Vogt KE, Miller RJ, Nicoll RA, Schmitz D (2003) Alpha1E-containing Ca2+ channels are involved in synaptic plasticity. Proc Natl Acad Sci U S A 100:12450-12455.

Caiati MD, Sivakumaran S, Lanore F, Mulle C, Richard E, Verrier D, Marsicano G, Miles R, Cherubini E (2012) Developmental regulation of CB1-mediated spike-time dependent depression at immature mossy fiber-CA3 synapses. Scientific Reports 2.

Carta M, Lanore F, Rebola N, Szabo Z, Da Silva SV, Lourenco J, Verraes A, Nadler A, Schultz C, Blanchet C, Mulle C (2014) Membrane lipids tune synaptic transmission by direct modulation of presynaptic potassium channels. Neuron 81:787-799.

Castillo PE, Malenka RC, Nicoll RA (1997) Kainate receptors mediate a slow postsynaptic current in hippocampal CA3 neurons. Nature 388:182-186.

Castillo PE, Younts TJ, Chavez AE, Hashimotodani Y (2012) Endocannabinoid signaling and synaptic function. Neuron 76:70-81.

Christopherson KS, Hillier BJ, Lim WA, Bredt DS (1999) PSD-95 assembles a ternary complex with the N-methyl-D-aspartic acid receptor and a bivalent neuronal NO synthase PDZ domain. J Biol Chem 274:27467-27473.

Claiborne BJ, Xiang Z, Brown TH (1993) Hippocampal circuitry complicates analysis of longterm potentiation in mossy fiber synapses. Hippocampus 3:115-121.

Contractor A, Rogers C, Maron C, Henkemeyer M, Swanson GT, Heinemann SF (2002) Transsynaptic Eph receptor-ephrin signaling in hippocampal mossy fiber LTP. Science 296:1864-1869.

Diamantaki M, Frey M, Berens P, Preston-Ferrer P, Burgalossi A (2016) Sparse activity of identified dentate granule cells during spatial exploration. Elife 5.

Dietrich D, Kirschstein T, Kukley M, Pereverzev A, von der Brelie C, Schneider T, Beck H (2003) Functional specialization of presynaptic Cav2.3 Ca2+ channels. Neuron 39:483496.

Feinmark SJ, Begum R, Tsvetkov E, Goussakov I, Funk CD, Siegelbaum SA, Bolshakov VY (2003) 12-lipoxygenase metabolites of arachidonic acid mediate metabotropic glutamate 
receptor-dependent long-term depression at hippocampal CA3-CA1 synapses. J Neurosci 23:11427-11435.

Fitzsimonds RM, Poo MM (1998) Retrograde signaling in the development and modification of synapses. Physiol Rev 78:143-170.

Gerber U, Gee CE, Benquet P (2007) Metabotropic glutamate receptors: intracellular signaling pathways. Curr Opin Pharmacol 7:56-61.

GoodSmith D, Chen X, Wang C, Kim SH, Song H, Burgalossi A, Christian KM, Knierim JJ (2017) Spatial Representations of Granule Cells and Mossy Cells of the Dentate Gyrus. Neuron 93:677-690 e675.

Griffith WH (1990) Voltage-clamp analysis of posttetanic potentiation of the mossy fiber to CA3 synapse in hippocampus. J Neurophysiol 63:491-501.

Henze DA, Urban NN, Barrionuevo G (2000) The multifarious hippocampal mossy fiber pathway: a review. Neuroscience 98:407-427.

Henze DA, Wittner L, Buzsaki G (2002) Single granule cells reliably discharge targets in the hippocampal CA3 network in vivo. Nat Neurosci 5:790-795.

Higley MJ, Sabatini BL (2008) Calcium signaling in dendrites and spines: practical and functional considerations. Neuron 59:902-913.

Hofmann ME, Nahir B, Frazier CJ (2008) Excitatory afferents to CA3 pyramidal cells display differential sensitivity to $\mathrm{CB} 1$ dependent inhibition of synaptic transmission. Neuropharmacology 55:1140-1146.

Jonas P, Major G, Sakmann B (1993) Quantal components of unitary EPSCs at the mossy fibre synapse on CA3 pyramidal cells of rat hippocampus. J Physiol 472:615-663.

Kamiya H, Shinozaki H, Yamamoto C (1996) Activation of metabotropic glutamate receptor type 2/3 suppresses transmission at rat hippocampal mossy fibre synapses. J Physiol 493 ( Pt 2):447-455.

Kano M, Ohno-Shosaku T, Hashimotodani Y, Uchigashima M, Watanabe M (2009) Endocannabinoid-mediated control of synaptic transmission. Physiol Rev 89:309-380.

Kapur A, Yeckel M, Johnston D (2001) Hippocampal mossy fiber activity evokes Ca2+ release in CA3 pyramidal neurons via a metabotropic glutamate receptor pathway. Neuroscience 107:59-69.

Katona I, Urban GM, Wallace M, Ledent C, Jung KM, Piomelli D, Mackie K, Freund TF (2006) Molecular composition of the endocannabinoid system at glutamatergic synapses. J Neurosci 26:5628-5637.

Kukley M, Schwan M, Fredholm BB, Dietrich D (2005) The role of extracellular adenosine in regulating mossy fiber synaptic plasticity. J Neurosci 25:2832-2837.

Kwon HB, Castillo PE (2008a) Role of glutamate autoreceptors at hippocampal mossy fiber synapses. Neuron 60:1082-1094.

Kwon HB, Castillo PE (2008b) Long-term potentiation selectively expressed by NMDA receptors at hippocampal mossy fiber synapses. Neuron 57:108-120.

Lawrence JJ, McBain CJ (2003) Interneuron diversity series: containing the detonation-feedforward inhibition in the CA3 hippocampus. Trends Neurosci 26:631-640.

Lledo PM, Zhang X, Sudhof TC, Malenka RC, Nicoll RA (1998) Postsynaptic membrane fusion and long-term potentiation. Science 279:399-403.

Maccaferri G, Toth K, McBain CJ (1998) Target-specific expression of presynaptic mossy fiber plasticity. Science 279:1368-1370. 
Marsicano G, Lutz B (1999) Expression of the cannabinoid receptor CB1 in distinct neuronal

Mellor J, Nicoll RA (2001) Hippocampal mossy fiber LTP is independent of postsynaptic calcium. Nat Neurosci 4:125-126.

Montal M (2010) Botulinum Neurotoxin: A Marvel of Protein Design. Annual Review of Biochemistry, Vol 79 79:591-617.

Moore KA, Nicoll RA, Schmitz D (2003) Adenosine gates synaptic plasticity at hippocampal mossy fiber synapses. Proc Natl Acad Sci U S A 100:14397-14402.

Mori M, Gahwiler BH, Gerber U (2007) Recruitment of an inhibitory hippocampal network after bursting in a single granule cell. Proc Natl Acad Sci U S A 104:7640-7645.

Nelson AB, Krispel CM, Sekirnjak C, du Lac S (2003) Long-lasting increases in intrinsic excitability triggered by inhibition. Neuron 40:609-620.

Nicoll RA, Schmitz D (2005) Synaptic plasticity at hippocampal mossy fibre synapses. Nat Rev Neurosci 6:863-876.

Pernia-Andrade AJ, Jonas P (2014) Theta-gamma-modulated synaptic currents in hippocampal granule cells in vivo define a mechanism for network oscillations. Neuron 81:140-152.

Regehr WG (2012) Short-Term Presynaptic Plasticity. Cold Spring Harbor Perspectives in Biology 4.

Regehr WG, Delaney KR, Tank DW (1994) The role of presynaptic calcium in short-term enhancement at the hippocampal mossy fiber synapse. J Neurosci 14:523-537. retrograde messengers. Neuron 63:154-170.

Reid CA, Fabian-Fine R, Fine A (2001) Postsynaptic calcium transients evoked by activation of individual hippocampal mossy fiber synapses. J Neurosci 21:2206-2214.

Roussel C, Erneux T, Schiffmann SN, Gall D (2006) Modulation of neuronal excitability by intracellular calcium buffering: from spiking to bursting. Cell Calcium 39:455-466.

Salin PA, Scanziani M, Malenka RC, Nicoll RA (1996) Distinct short-term plasticity at two excitatory synapses in the hippocampus. Proc Natl Acad Sci U S A 93:13304-13309.

Sattler R, Xiong Z, Lu WY, Hafner M, MacDonald JF, Tymianski M (1999) Specific coupling of NMDA receptor activation to nitric oxide neurotoxicity by PSD-95 protein. Science 284:1845-1848.

Scanziani M, Salin PA, Vogt KE, Malenka RC, Nicoll RA (1997) Use-dependent increases in glutamate concentration activate presynaptic metabotropic glutamate receptors. Nature 385:630-634.

Schiavo G, Matteoli M, Montecucco C (2000) Neurotoxins affecting neuroexocytosis. Physiol Rev 80:717-766.

Senzai Y, Buzsaki G (2017) Physiological Properties and Behavioral Correlates of Hippocampal Granule Cells and Mossy Cells. Neuron 93:691-704 e695.

Simons SB, Escobedo Y, Yasuda R, Dudek SM (2009) Regional differences in hippocampal calcium handling provide a cellular mechanism for limiting plasticity. Proc Natl Acad Sci U S A 106:14080-14084.

Toth K, Suares G, Lawrence JJ, Philips-Tansey E, McBain CJ (2000) Differential mechanisms of transmission at three types of mossy fiber synapse. J Neurosci 20:8279-8289.

Treves A, Rolls ET (1992) Computational constraints suggest the need for two distinct input systems to the hippocampal CA3 network. Hippocampus 2:189-199. 
1 Urban NN, Henze DA, Barrionuevo G (2001) Revisiting the role of the hippocampal mossy fiber synapse. Hippocampus 11:408-417.

Vandael D, Borges-Merjane C, Zhang X, Jonas P (2020) Short-Term Plasticity at Hippocampal Mossy Fiber Synapses Is Induced by Natural Activity Patterns and Associated with Vesicle Pool Engram Formation. Neuron 107:509-521 e507.

Verkhratsky A (2005) Physiology and pathophysiology of the calcium store in the endoplasmic reticulum of neurons. Physiol Rev 85:201-279.

Vyleta NP, Borges-Merjane C, Jonas P (2016) Plasticity-dependent, full detonation at hippocampal mossy fiber-CA3 pyramidal neuron synapses. Elife 5.

Wang J, Yeckel MF, Johnston D, Zucker RS (2004) Photolysis of postsynaptic caged Ca2+ can potentiate and depress mossy fiber synaptic responses in rat hippocampal CA3 pyramidal neurons. J Neurophysiol 91:1596-1607.

Weisskopf MG, Nicoll RA (1995) Presynaptic changes during mossy fibre LTP revealed by NMDA receptor-mediated synaptic responses. Nature 376:256-259.

Williams SR, Mitchell SJ (2008) Direct measurement of somatic voltage clamp errors in central neurons. Nat Neurosci 11:790-798.

Yeckel MF, Kapur A, Johnston D (1999) Multiple forms of LTP in hippocampal CA3 neurons use a common postsynaptic mechanism. Nat Neurosci 2:625-633.

Zalutsky RA, Nicoll RA (1990) Comparison of two forms of long-term potentiation in single hippocampal neurons. Science 248:1619-1624.

Zucker RS, Regehr WG (2002) Short-term synaptic plasticity. Annu Rev Physiol 64:355-405. 
Figure 1. High postsynaptic $\mathrm{Ca}^{2+}$ buffering selectively enhances post-tetanic potentiation

at the MF-CA3 synapse. (a) Summary data showing the effect of loading the patch pipette with 10 mM BAPTA on PTP of AMPAR-mediated MF-responses compared to control condition (0.1 mM EGTA) (Control: $125 \pm 52 \%$ of baseline; $n=6$; BAPTA: $347 \pm 84 \%$; $=6$; Control vs. BAPTA: $\mathrm{p}<0.05)$. Experiments were performed at $32{ }^{\circ} \mathrm{C}, \mathrm{Vh}=-60 \mathrm{mV}$, with only a low concentration of the AMPAR selective antagonist GYKI-53655 (1 $\mu \mathrm{M})$, and the bursting paradigm was performed in current-clamp mode. AMPAR-EPSCs were evoked with bulk stimulation in the GC layer. At

10 the end of the experiments, DCG-IV $(1 \mu \mathrm{M})$ was added to the bath to verify that the synaptic 11 responses were mediated by MF activation. PTP is quantified as the average of the EPSCs during the first three minutes post-induction vs the three minutes prior induction. Representative traces (top) and time-course summary plot (bottom). (b) Summary data of experiments in which the same bursting paradigm was performed at the neighboring associational-commissural (CA3CA3) synapse. Note no difference between control and BAPTA-dialyzed cells (Control: $101 \pm$ $6 \%$; $=5$; BAPTA: $95 \pm 3 \% ; n=7$; Control vs. BAPTA: $p>0.3$ ). NBQX was used at the end of the

17 experiments to confirm AMPAR-mediated responses. (c) PTP assessed by minimal stimulation 18 of MFs while monitoring AMPAR-EPSCs in the absence of drugs in the bath. PTP was induced

19 in current-clamp mode. Left, representative traces showing successes (black) and failures

20 (grey). Right, summary data showing MF-PTP elicited with minimal stimulation in control and 21 BAPTA-dialyzed cells (Control: $112 \pm 27$ of baseline; $n=6$; BAPTA: $354 \pm$ 82; $n=6$; Control vs.

22 BAPTA: $p$ < 0.05). (d) PPR was not affected by intracellular 10 mM BAPTA loading (Control: 2.5 $23 \pm 0.18 ; n=10 ;$ BAPTA: $2.3 \pm 0.17 ; n=6$; Control vs. BAPTA: $p>0.5)$. Number of cells are

24 indicated between brackets.

25 Here and in all figures, data are presented as mean \pm SEM; representative traces correspond to 26 the time points indicated by numbers on the time-course plots. 
Figure 2. Weak MF-PTP of KAR-mediated transmission under physiological postsynaptic $\mathrm{Ca}^{2+}$ buffering recording conditions. (a) Summary data showing the effect of $10 \mathrm{mM}$ BAPTA on MF-PTP (Control: $115 \pm 6 \%$; n=6; BAPTA: $203 \pm 14 \%$; $=7$; Control vs. BAPTA: $p<0.001$ ). (b) Summary data for Control vs 10 mM EGTA (Control: $122 \pm 13 \%, n=7$; 10 mM EGTA: $196 \pm$ $17 \%$ of baseline, $n=6$; Control vs 10 mM EGTA p<0.01). (c) Left, Summary effect when 10 mM BAPTA was included in the recording pipette, in whole-cell vs. perforated-patch configuration (BAPTA perforated patch: $138 \pm 11 \%$; $n=7$; BAPTA whole cell: $226 \pm 11 \%$; $n=4$; BAPTA perforated patch vs. BAPTA whole-cell: $p<0.001)$. Right, EPSPs from representative

10 experiments.

Figure 3. Enhanced MF-PTP by high postsynaptic $\mathrm{Ca}^{2+}$ buffering capacity is presynaptically expressed. (a) Summary data showing the effect of 25 bursts on NMDARmediated EPSCs $\left(\mathrm{V}_{\mathrm{H}}=-50 \mathrm{mV}\right)$, when CA3 neurons were dialyzed with control vs BAPTA intracellular solution (control: $102 \pm 11 \%$ of baseline; $n=5$; BAPTA: $191 \pm 23 \%$; $n=7$; control vs. BAPTA: $p<0.05$ ). (b) Summary plot of the AMPAR-mediated MF response after the bursting 17 paradigm, in control vs. BAPTA conditions (control: $135 \pm 17 \%$; $n=6$; BAPTA: $223 \pm 16 \%$; $n=7$; control vs. BAPTA: p<0.01). (c) KAR PPR was monitored by delivering two pulses (40 ms inter-

19 stimulus interval). Top, Averaged traces from representative experiments, before and after 20 bursting, and summary plot of the first EPSC amplitude in control vs. BAPTA solutions. Bottom, 21 Summary of PPR time course as normalized to the three minutes before the bursting paradigm.

22 Same cells as in top panel (Control: $80 \pm 8 \%$; $n=7$; BAPTA: $37 \pm 5 \%$; $n=6$; control vs. BAPTA: $23 \mathrm{p}<0.01)$.

25 Figure 4. Suppression of MF-PTP depends on internal $\mathrm{Ca}^{2+}$ stores. (a) Summary effect of 26 voltage-clamping cells at $-80 \mathrm{mV}$ with $25 \mu \mathrm{M}$ nifedipine in the bath in control and BAPTA- 
1 dialyzed cells (Control: $138 \pm 3 \%$; $n=5$; BAPTA: $209 \pm 20 \%$; $n=5$; control vs. BAPTA: $p<0.01$ ).

2 (b) Summary effect of adding $100 \mu \mathrm{M} \mathrm{Ni}^{2+}$ and $10 \mu \mathrm{M}$ nimodipine to the bath (Control: $110 \pm 14$;

$3 n=9$; BAPTA: $151 \pm 9$; $n=8$; control vs. BAPTA: $p<0.05)$. (c) Summary effect of including

4 cyclopiazonic acid (CPA) in the patch pipette (Control: $112 \pm 6 \%$; $n=4 ;$ CPA: $156 \pm 16 \%$; $=5$;

5 Control vs CPA: $p<0.05)$. (d) Summary effect of including heparin in the recording pipette to

6 block IP3Rs (Control: $112 \pm 2 \%$; $n=5$; heparin: $157 \pm 17 \%$; $n=5$; Control vs heparin: $p<0.05$ ).

8 Figure 5. Assessing the mechanism underlying MF-PTP suppression. (a) Summary of data

9 of MF-PTP under control (0.1 mM EGTA) and high intracellular buffering conditions (10 mM

10 BAPTA) in the presence of the Group I mGluR antagonists MPEP and CPCCOEt (Control: 122

$11 \pm 6 \%$; $n=6$; BAPTA: $208 \pm 28 \%$; $n=6$; control vs. BAPTA: $p<0.05$ ). (b) Summary data of

12 experiments in which control and BAPTA cells were dialyzed with GDP- $\beta$ S (Control-GDP- $\beta S$ :

$13106 \pm 13 \%$; n=5; BAPTA-GDP- $\beta S: 161 \pm 17 \%$; $n=5$; control-GDP- $\beta S$ vs. BAPTA-GDP- $\beta S$ :

$14 \mathrm{p}<0.05)$. (c) Cells dialyzed with botulinum toxin B (BoTX) did not exhibit any more PTP than

15 interleaved controls without BoTX (BoTX included in control solution: $116 \pm 2 \%$; $n=5$; BAPTA

16 without BoTX: $189 \pm 16 \%$; $n=5$; control-BoTX vs. BAPTA: $p<0.01$ ). (d) Summary data when a

17 cocktail of lipid blockers (ETYA, indomethacin, and RHC-80267) was included in the intracellular

18 recording solution (Control: $105 \pm 6 \%$ of baseline; $n=6$; BAPTA: $220 \pm 21 \%$; $n=4$; control vs.

19 BAPTA: $p<0.001$ ). (e) Summary data showing no PTP in control cells after bursting paradigm in

20 the presence of the adenosine 1 receptor antagonist DPCPX, whereas robust PTP observed in

21 BAPTA-dialyzed cells (Control: $104 \pm 3 \%$; $n=5$; BAPTA: $191 \pm 7 \%$; $n=4$; control vs. BAPTA:

$22 \mathrm{p}<0.001)$. (f) Summary data showing the effect of bursting paradigm in control and BAPTA-

23 dialyzed cells in the presence of the Group II and III mGluR antagonists LY-341495 and MSOP

24 (Control: $121 \pm 10 \%$; n=6; BAPTA: $201 \pm 10 \%$; $n=4$; control vs. BAPTA: $p<0.001$ ). 
1 Figure 6. MF-PTP suppression under different patterns of activity. (a) Five pulses were

2 delivered to MFs for control and BAPTA-dialyzed cells, and the ratio of the fifth KAR-EPSC to

3 the first was taken (P5/P1 control: $6.0 \pm 0.7 ; n=12 ;$ P5/P1 BAPTA: $6.5 \pm 0.9 ; n=13$; control vs.

4 BAPTA: $p>0.5$ ). Traces normalized to the amplitude of first EPSC. (b) Summary data showing

5 effect of switching basal stimulation frequency from 0.1 to $1.0 \mathrm{~Hz}$ in control vs. BAPTA-dialyzed

6 cells (LFF control: $341 \pm 73 \%$ of baseline; $n=6$; LFF BAPTA: $358 \pm 59 \%$; $n=6$; control vs.

7 BAPTA: $p>0.5$ ). Insets: superimposed traces taken at 0.1 and $1.0 \mathrm{~Hz}$. Calibration bars: $40 \mathrm{pA}$

8 and 40 ms. (c) Summary data showing the suppressive effect on MF-PTP induced by different

9 number of bursts. Three bursts, control: $101 \pm 5 \%$ of baseline; $n=7 ;$ BAPTA: $102 \pm 4 \%$; $n=5$

10 (control vs. BAPTA: $p>0.5$ ). Ten bursts, control: $121 \pm 7 \%$ of baseline; $n=8 ;$ BAPTA: $167 \pm 14 \%$;

$11 \mathrm{n}=7$ (control vs. BAPTA: $p<0.01$ ). Twenty-five bursts: control: $115 \pm 6 \%$ of baseline; $n=7$;

12 BAPTA: $203 \pm 14 \%$; $n=7$ (control vs. BAPTA: $p<0.001$ ). Fifty bursts: control: $147 \pm 10 \%$ of

13 baseline; $n=8$; BAPTA: $264 \pm 15 \%$; $n=6$ (control vs. BAPTA: $p<0.001$ ). (d) Effect of high

14 frequency stimulation (HFS; 100 pulses at $100 \mathrm{~Hz}, \mathrm{x} 3$ ) on MF KAR-EPSCs, with or without

15 BAPTA in the patch pipette (Control: $181 \pm 20 \%$ of baseline; $n=7 ;$ BAPTA: $282 \pm 24 \%$; $n=5$;

16 control vs. BAPTA: $p<0.01)$. (e-h) Effects of MF-PTP on CA3 pyramidal neuron firing induced by

17 MF bursting stimulation. No drugs were added to the bath .Control cells loaded with $0.1 \mathrm{mM}$

18 EGTA (e,f) showed little-to-no action potentials before and after PTP (Baseline: $0 \pm 0 \%$; $n=6$;

19 PTP: $2 \pm 2 \%$; $n=6$; baseline vs. PTP: $p>0.4$, Mann-Whitney), whereas in cells loaded with 10

20 mM BAPTA $(\mathrm{g}, \mathrm{h})$ PTP enhanced the probability of firing action potentials (baseline: $27 \pm 9 \%$;

$21 \mathrm{n}=6$; PTP: $42 \pm 11 \%$; $\mathrm{n}=6$; baseline vs. PTP: $p<0.005$, paired t-test). 


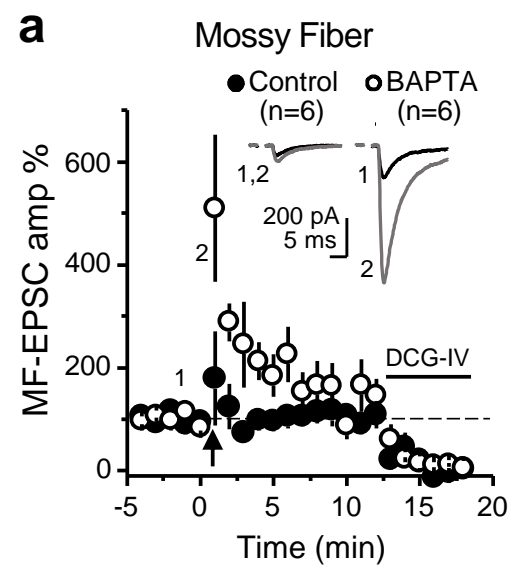

b Associational-Commissural
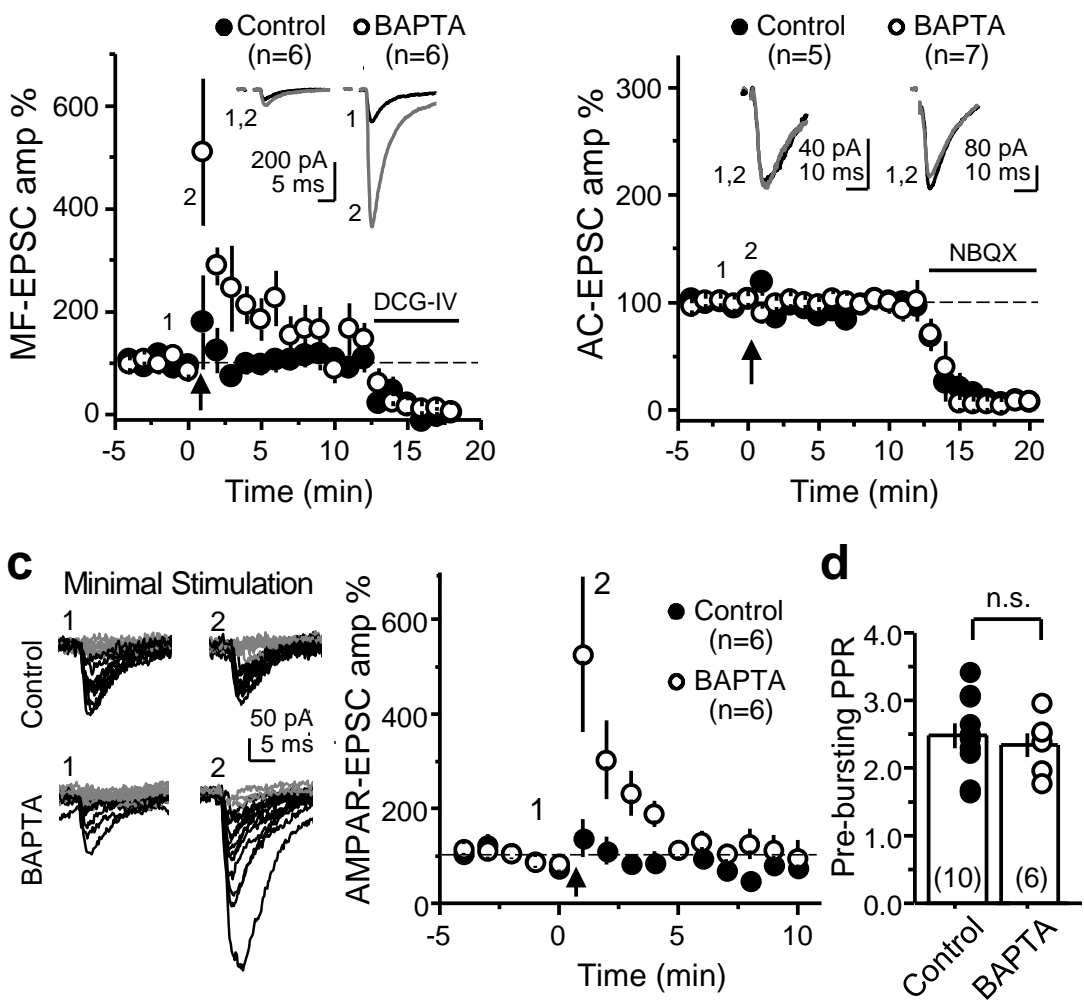

Figure 1. High postsynaptic $\mathrm{Ca}^{2+}$ buffering selectively enhances posttetanic potentiation at the MF-CA3 synapse. 

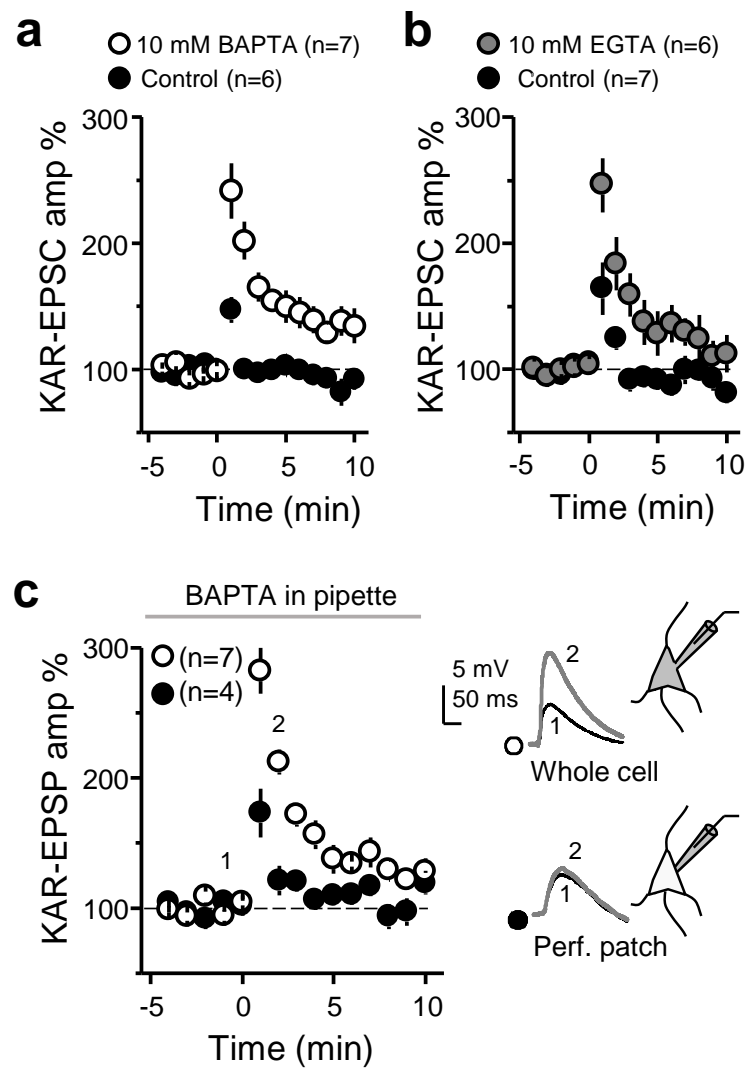

Figure 2. Weak MF-PTP of KAR-mediated transmission under physiological postsynaptic $\mathrm{Ca}^{2+}$ buffering recording conditions. 

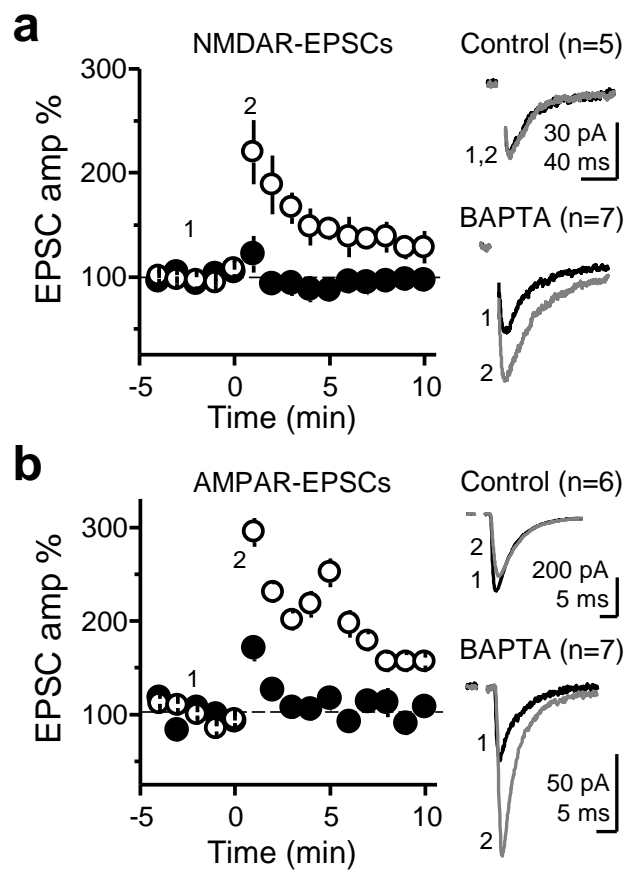

Control $(n=6)$

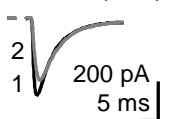

$\operatorname{BAPTA}(n=7)$
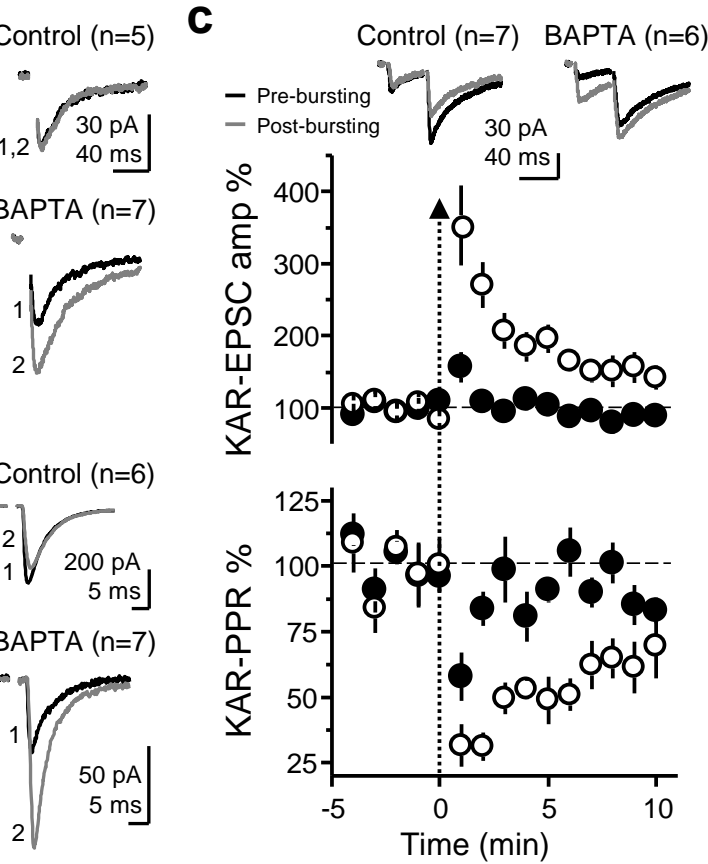

Figure 3. Enhanced MF-PTP by high postsynaptic $\mathrm{Ca}^{2+}$ buffering capacity is presynaptically expressed. 


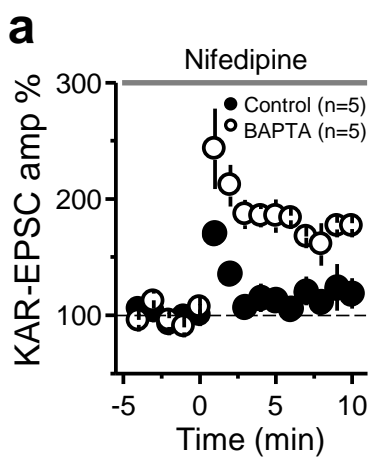

b
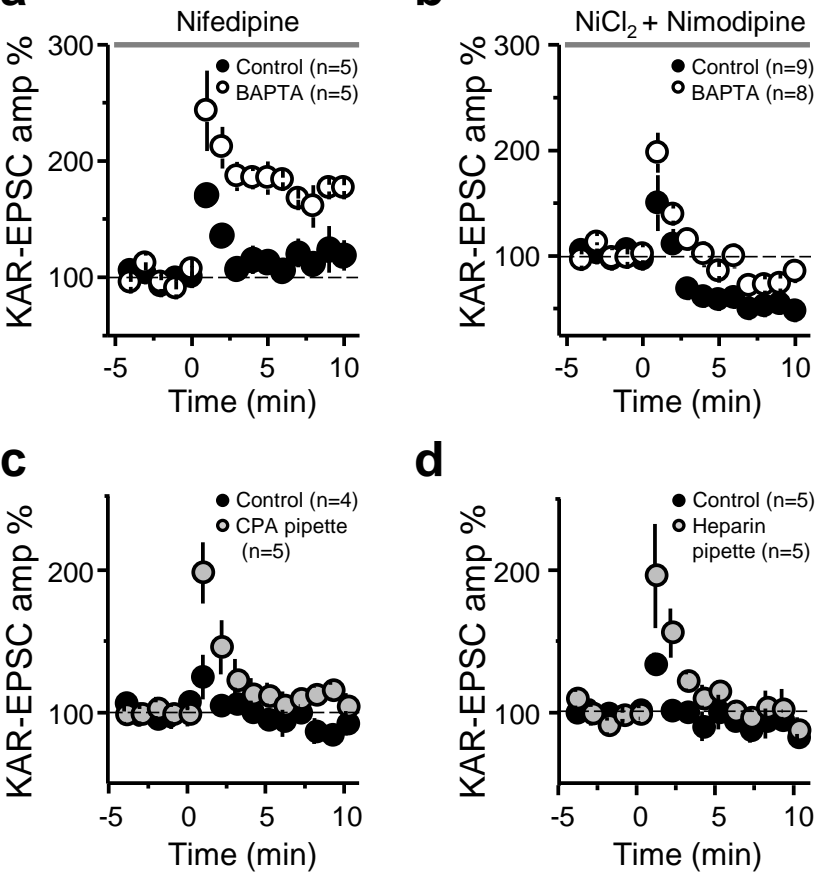

d

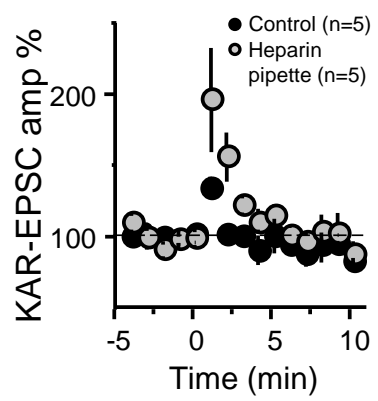

Figure 4. Suppression of MF-PTP depends on internal $\mathrm{Ca}^{2+}$ stores. 
a

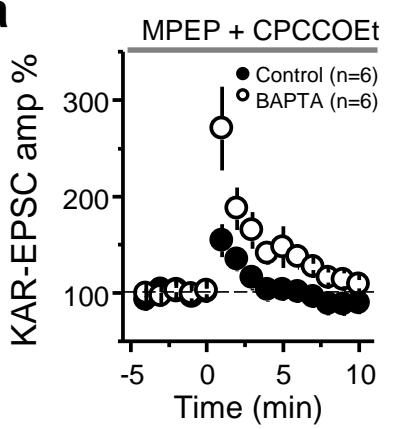

C

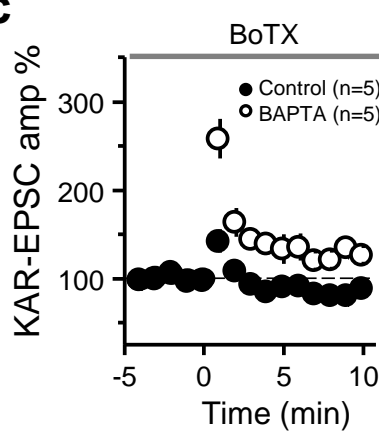

e

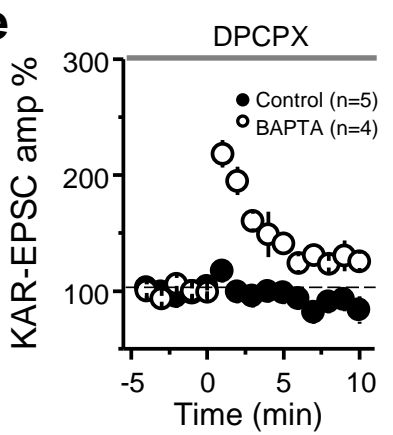

b

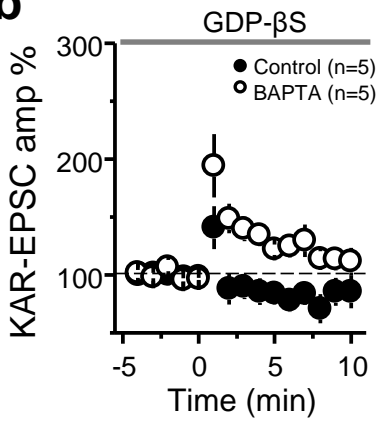

d

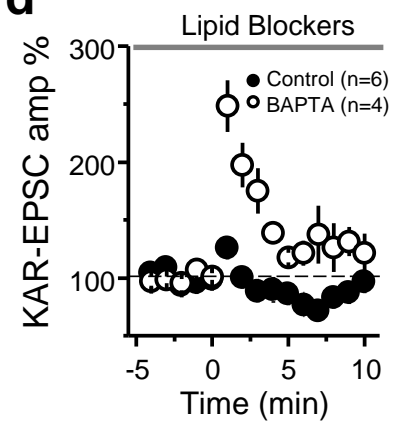

f

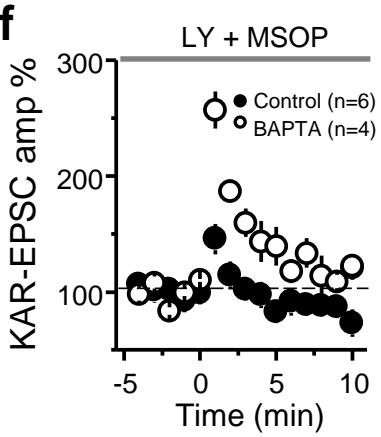

Figure 5. Assessing the mechanism underlying MF-PTP suppression. 
a

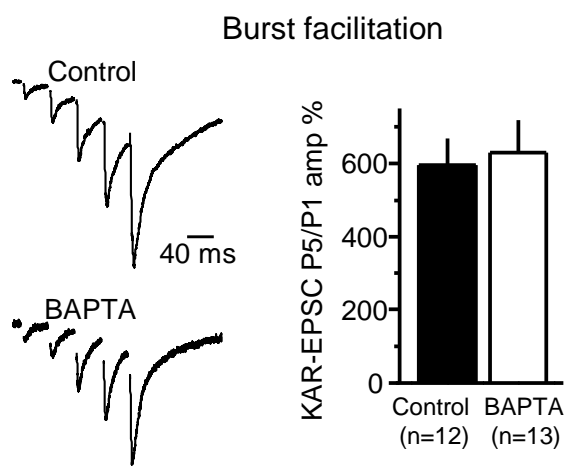

C

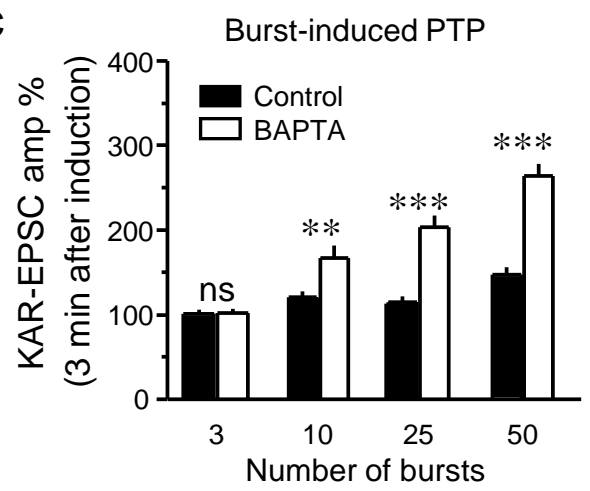

e

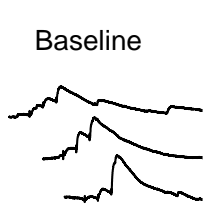

Control (0.1 mM EGTA)

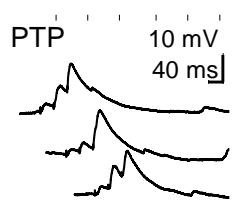

g
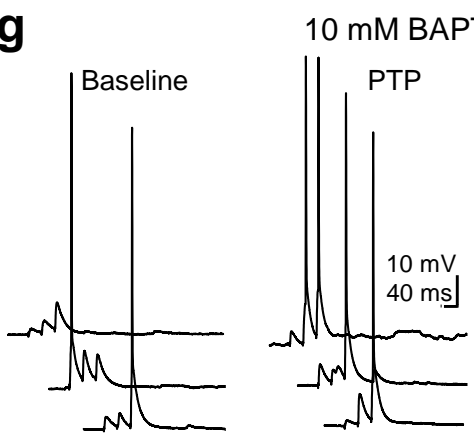
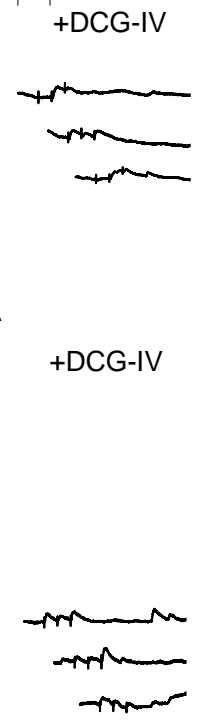
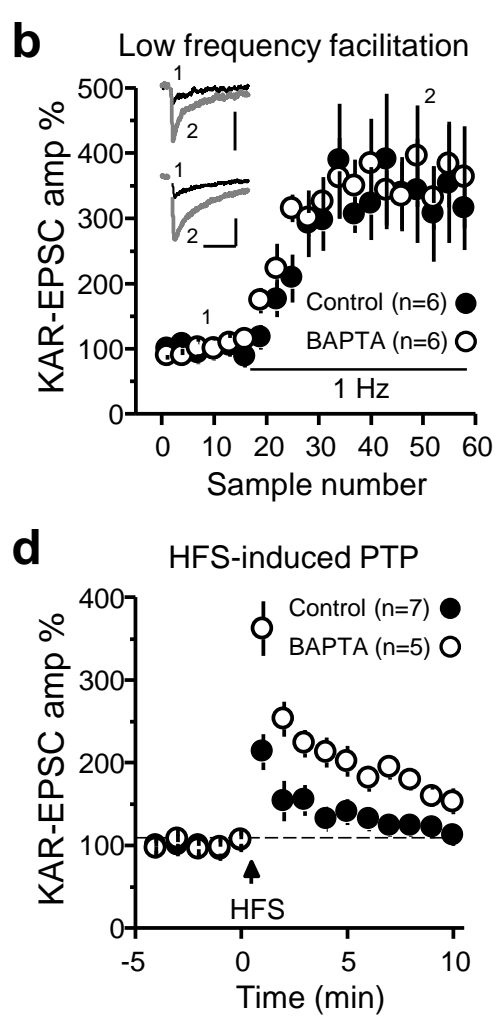

f

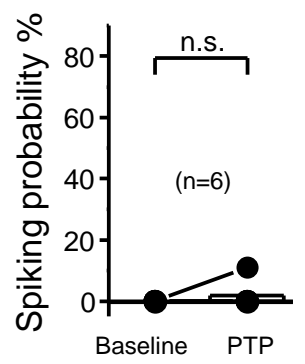

h + DCG-IV

Figure 6. MF-PTP suppression under different patterns of activity. 

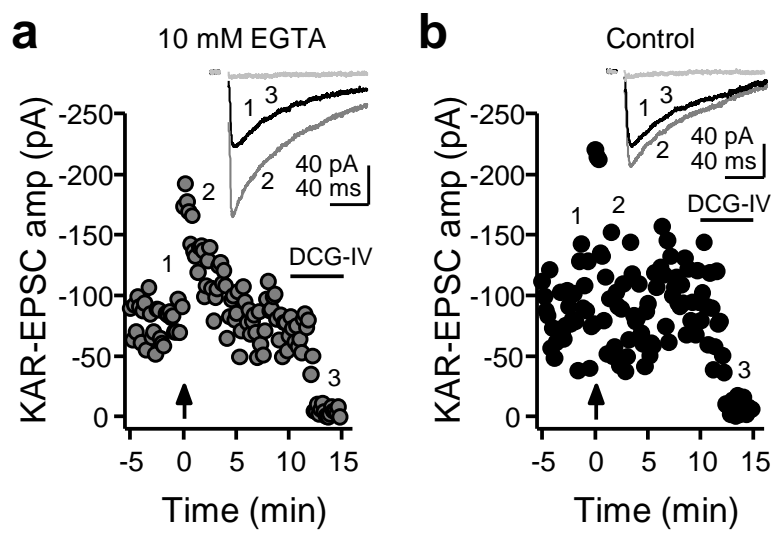

Extended Figure 2. (a) Representative experiment in which the recording pipette solution contained $10 \mathrm{mM} \mathrm{EGTA}$. KAREPSC traces, which correspond to the numbers in the time course plot below, are shown above. DCG-IV $(1 \mu \mathrm{M})$ was added at the end of the experiment. (b) Representative experiment in which the pipette solution contained $0.1 \mathrm{mM}$ EGTA (Control). Note suppression of PTP relative to (a). 
a

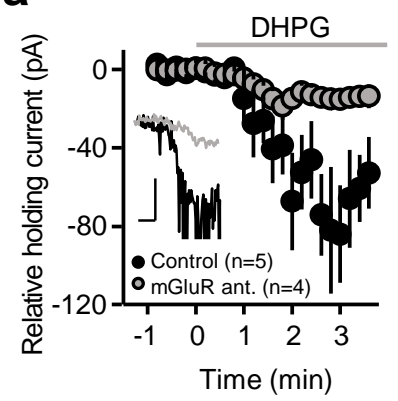

C Pairing Protocol-CA1 LTP

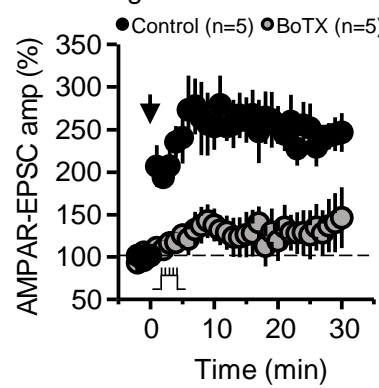

e

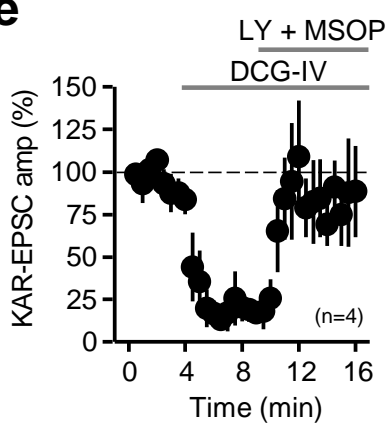

b

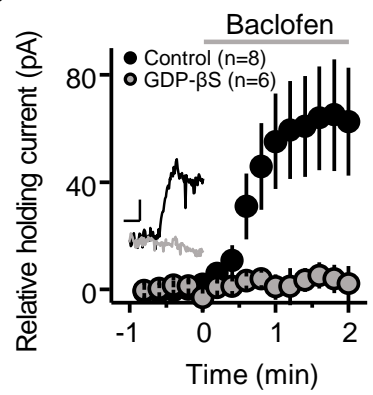

d

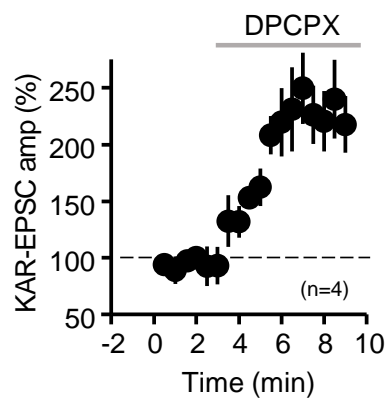

Extended Figure 5 (a) Bath application of the group I mGluR agonist DHPG (50 $\mu \mathrm{M})$ caused an inward current, was significantly reduced in the presence of the group I mGluR antagonists MPEP/CPCCOEt. (Control: $55 \pm 11 \mathrm{pA} ; n=5$; MPEP/CPCCOEt: $14 \pm 5 \mathrm{pA} ; n=4$; control vs. antagonists: $p<0.05)$. Inset: superimposed traces in control and in the presence of MPEP/CPCCOEt. Calibration bars: 40 pA, 1 min. (b) The outward current induced by bath application of the GABA agonist baclofen was abolished by intracellular loading of GDP- $\beta S$ (Control: $61 \pm 19$ pA; $n=8$; GDP$\beta S$ : $3 \pm 6 p A ; n=6$; Control vs. GDP- $\beta S$ : $p<0.05)$. Inset: superimposed representative traces in control cells (black) and cells loaded with GDP- $\beta$ S. Calibration bars: 40 pA, 1 min. (c) Loading BoTX in CA1 pyramidal neurons blocked LTP of AMPAR-mediated transmission (Control: $240 \pm 18 \%$ of baseline; $n=5$; BoTX: $137 \pm 30 \%$; $n=5$; Control vs. BoTX: $p<0.05)$. LTP was generated using a pairing protocol of postsynaptic depolarization (from $\mathrm{V}_{\mathrm{H}}=-60$ to $0 \mathrm{mV}$ ) for three minutes, and stimulating the Schaffer collaterals with 180 pulses $(2 \mathrm{~Hz})$. (d) Positive control showing the immediate potentiating effect of $200 \mathrm{nM}$ DPCPX (221 $\pm 25 \%$ of baseline, $n=4 ; \mathrm{p}<0.01)$. (e) The suppression of MF-mediated responses by $1 \mu \mathrm{M}$ DCG-IV bath application was reversed by the antagonists LY341495 $(1 \mu \mathrm{M})$ and MSOP $(200 \mu M)(90 \pm 24 \%$ of original baseline; $n=4)$. 